\title{
DNA Replication Inhibitor Geminin and Retinoic Acid Signaling Participate in Complex Interactions Associated With Pluripotency
}

\author{
SPYRIDON CHAMPERIS TSANIRAS ${ }^{1,2}$, GEORGE J. DELINASIOS ${ }^{3}$, MICHALIS PETROPOULOS $^{4}$, \\ ANDREAS PANAGOPOULOS ${ }^{4}$, ATHANASIOS K. ANAGNOSTOPOULOS ${ }^{3,5}$, MARIA VILLIOU ${ }^{1}$, \\ DIMITRIOS VLACHAKIS ${ }^{6}$, VASILIKI BRAVOU ${ }^{7}$, GEORGIOS T. STATHOPOULOS ${ }^{8}$ and STAVROS TARAVIRAS $^{1}$ \\ ${ }^{1}$ Department of Physiology, Medical School, University of Patras, Patras, Greece; \\ ${ }^{2}$ Cold Spring Harbor Laboratory, Cold Spring Harbor, NY, U.S.A.; \\ ${ }^{3}$ International Institute of Anticancer Research, Kapandriti, Greece; \\ ${ }^{4}$ Department of Biology, School of Medicine, University of Patras, Patras, Greece; \\ ${ }^{5}$ Proteomics Research Unit, Biomedical Research Foundation of the Academy of Athens, Athens, Greece; \\ ${ }^{6}$ Bioinformatics \& Medical Informatics Laboratory, \\ Biomedical Research Foundation of the Academy of Athens, Athens, Greece; \\ ${ }^{7}$ Department of Anatomy-Histology-Embryology, Faculty of Medicine, University of Patras, Patras, Greece; \\ ${ }^{8}$ Laboratory for Molecular Respiratory Carcinogenesis, \\ Department of Physiology, Faculty of Medicine, University of Patras, Patras, Greece
}

\begin{abstract}
Background/Aim: Several links between DNA replication, pluripotency and development have been recently identified. The involvement of miRNA in the regulation of cell cycle events and pluripotency factors has also gained attention. Materials and Methods: In the present study, we used the g:Profiler platform to analyze transcription factor binding sites, miRNA networks and protein-protein interactions to identify novel links among the aforementioned processes. Results and Conclusion: A complex circuitry between retinoic acid signaling, SWI/SNF components, pluripotency factors including Oct4, Sox2 and Nanog and cell cycle regulators was identified. It is suggested that the DNA replication inhibitor geminin plays a central role in this circuitry.
\end{abstract}

The maintenance of genome stability in living cells is associated with the tight regulation of DNA replication and integrity, so that the genome is fully and accurately replicated during each cell cycle. In eukaryotes, the initial

This article is freely accessible online.

Correspondence to: Stavros Taraviras, Department of Physiology, Medical School, University of Patras, Patras, Greece. E-mail: taraviras@med.upatras.gr

Key Words: DNA replication, geminin, Oct4, retinoic acid, pluripotency, mir-452, GABA, H2AX. steps of replication consist of the sequential assembly of prereplicative complex (pre-RC) proteins onto the origins of replication. This process is named replication licensing and takes place during a restricted window of time from late mitosis to early $\mathrm{G} 1(1,2)$. The pre-RCs consist of several proteins, including ORC, Cdt1, Cde6 and MCM 2-7. Restriction of replication licensing from the end of mitosis to early G1 occurs by regulating Cdt1 levels, either by ubiquitin-mediated degradation of Cdt1 or inhibition by geminin (3). Geminin plays a central role in preventing DNA re-replication, a process that can lead to genomic instability and cancer development (3-5).

Geminin is a small nuclear protein $(\sim 25 \mathrm{kDa})$ that plays a critical role in cell cycle regulation by inhibiting DNA replication $(6,7)$. Geminin binds to and inhibits the DNA replication factor Cdt1. It is expressed in the $S$ and $G_{2}$ phases of the cell cycle and is degraded by the anaphase-promoting complex during the metaphase-anaphase transition (8).

Geminin has been found to up-regulate transcription of the geminin gene, suggesting that its expression may be regulated by a molecular feedback loop (9). Although GMNN is transcriptionally regulated by E2F family members, the mechanism by which geminin modulates E2F-mediated transcriptional regulation of the GMNN gene is not fully understood (10). Geminin ablation has been reported to enhance colon and lung carcinogenesis (4) while it has also been found to be overexpressed in several human cancers including colon, rectal, oral and breast cancer (11-13). 
Similarly to other pre-RC components, geminin has been implicated in development and differentiation (14-16). In Xenopus embryos, it has been shown to induce cell differentiation contributing to the formation of the neural tube (17), while it has also been found to regulate the Hox homeobox proteins, controlling differentiation and proliferation (18). In another study with embryonic stem cells, geminin ablation was found to lead to loss of pluripotency and mesendodermal differentiation (19).

In the present article, we explored the interplay that seems to link the areas of DNA replication, pluripotency, development and cancer $(14,15,20-22)$. Our main focus was to identify common regulatory nodes among networks of pluripotency and oncogenic factors, development and components of DNA replication. In this direction, we reexamined recent experimental data, in conjunction with in silico predictions placing retinoic acid and geminin on the forefront of this network.

\section{Materials and Methods}

The web-based g:GOSt tool from the g:Profiler platform was used to identify functional information and enriched pathways and processes from gene lists (23-25). Data for predictions of transcription factor binding sites were derived from the TRANSFAC database (26), protein-protein interactions from the BioGRID database (27) and miRNA target sites from the miRBase database (28). In all cases, multiple testing correction was performed using the $\mathrm{g}: \mathrm{SCS}$ algorithm that is the default and most stringent algorithm for multiple testing corrections that are not independent of each other (23). A $p$-value $<0.05$ was considered to indicate statistically significant differences. The organism parameter was set to 'Homo sapiens (human)'. The generated data of transcription factor predictions and protein-protein interactions are depicted in Figure 1 while miRNA-mRNA UTR binding targets were used to construct an interaction network, and visualized using the open source software Cytoscape (version 3.3.0, USA) (Figure 2).

\section{Results and Discussion}

The present bioinformatic analysis is discussed along with significant findings from the literature. Our analysis was divided in several sub-sections in order to examine the involvement of geminin in specific interactions and signaling, shedding light to its pivotal role in certain complex regulatory processes in the mammalian cell machinery.

Geminin, pluripotency factors, and retinoic acid interactions

Geminin has been reported to be essential for maintaining Oct4, Sox2 and Nanog expression $(19,29)$ by antagonizing Brg1, a chromatin remodeling protein, and indirectly activating the Sox2 SRR2 enhancer (19); thus, keeping cells in a pluripotent state. In the chick embryo, there is strong evidence that it induces expression of the Sox2 SRR1 enhancer as well, through Brm, a subunit of SWI/SNF (30). Geminin has also been reported to act downstream of retinoic acid (RA) signaling; during primary neurogenesis, RA up-regulates the ERF and ETV3L transcriptional repressors which, in turn, have been reported to restrict geminin expression (31).

\section{Bioinformatic analysis results concur with current literature}

Evidence for Oct 4 and geminin regulation by RAR. In the present study we used the $\mathrm{g}$ :Profiler platform $(23,24)$ in order to identify potential shared transcription factor (TF) binding sites from the TRANSFAC database (26). Interestingly, the Oct4 and geminin genomic loci were predicted to have binding sequences for the retinoic acid receptor (RAR) ( $p=0.016$; $\mathrm{g}: \mathrm{SCS}$ algorithm) (Figure 1), which is a TF as well as a nuclear receptor (32).

Retinoic acid (RA) has been reported to inhibit Oct4 expression during embryonic stem (ES) cell differentiation indirectly, by repressing a cis enhancer element (33), as well as silencing its promoter (34). However, in these experiments, the role of RAR in mediating the RA effects was not assessed.

RAR has been reported to modulate the expression of cmyc as well as several Hox genes (including HoxB4, HoxB7, HoxA9 and HoxA10) (35), while our recent microarray data have shown that geminin ablation in the murine haematopoietic system results in significant RAR upregulation $(36,37)$. Interestingly, RA has also been shown to suppress Nanog, Oct4, geminin and Hox gene expression; however, the exact mechanism and whether it acts directly or indirectly, through RAR and/or other factors, is not known (Figure 1). More importantly, in a recent study, RA was reported to induce chromatin remodeling close to the Oct4 and Nanog genes and suppress their expression. This effect was dependent on a complex of RAR, receptor-interacting protein 140 (RIP140) and Brm. Using chromatin immunoprecipitation, the authors showed that Brm replaces another SWI/SNF subunit, Brg1, in this complex upon RAinduced repression, in the promoters of the aforementioned genes (38). In accordance with these data, Flajollet et al. (39) have also shown that RAR physically interacts with $\operatorname{Brg} 1$, as well as the SMARCD3/BAF606 complex, a core SWI/SNF subunit, which was eventually identified as a co-activator for RAR-induced transcription (Figure 1).

An interesting point is that during neural development, geminin has also been shown to directly interact with $\mathrm{Brg} 1$ and antagonize its activity, in order to maintain the cells in a multipotent state $(29,40,41)$. Adding another layer of complexity, geminin is also known to interact with Hox genes, both directly and indirectly, through Polycomb (18, 36) (Figure 1) while BRG1 is known to control Nanog transcription through histone deacetylation (42) and occupy the promoters of Oct4, Sox2 and Nanog (43). 


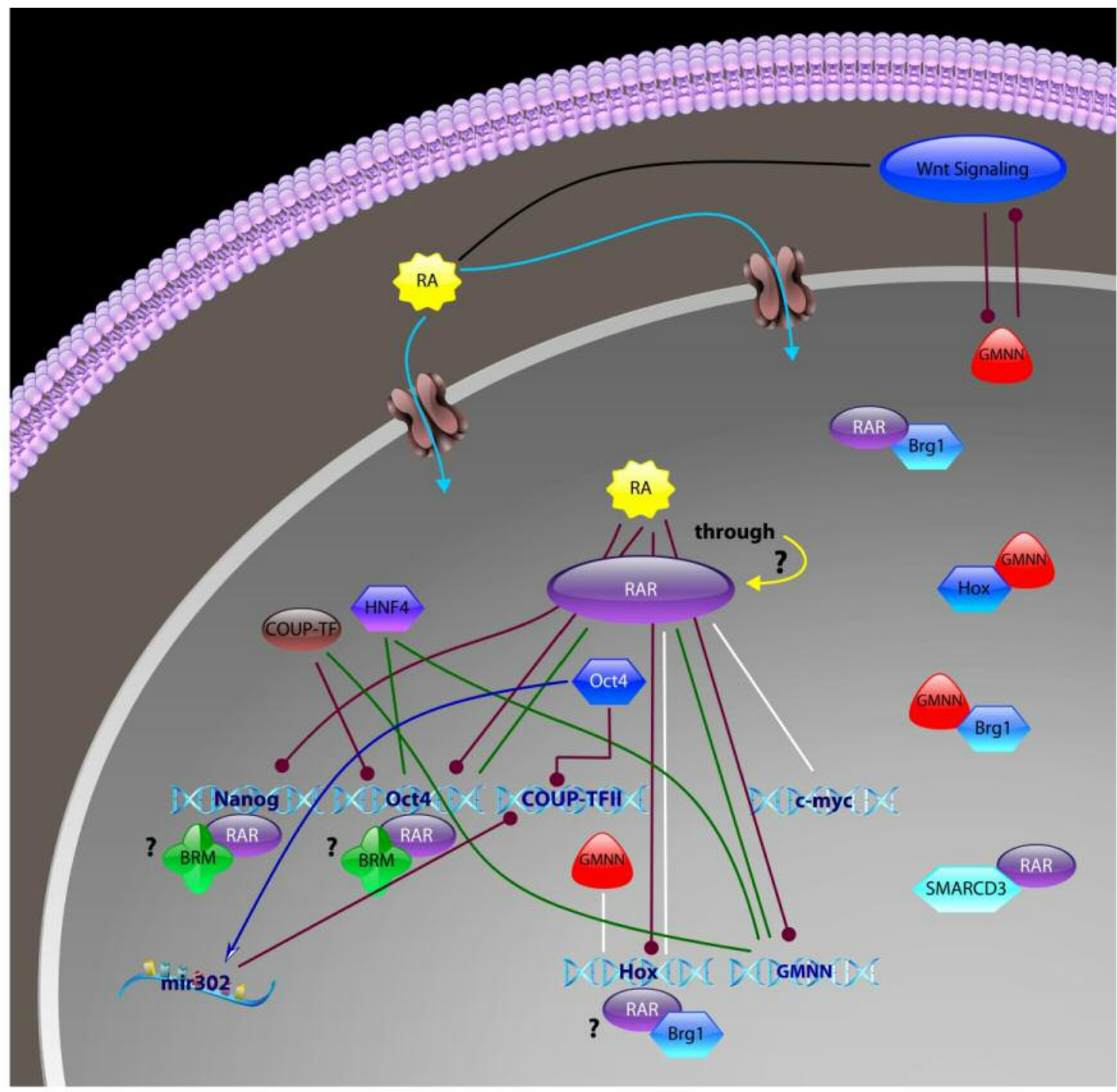

Figure 1. The signaling events involving geminin, RA signaling and pluripotency factors. RA modulates Wnt signaling (shown in black). Once inside the nucleus, it inhibits Nanog, Oct4, geminin (Gmnn) and Hox gene expression (shown in red), however, whether it mediates these effects through RAR is not known. In turn, RAR modulates Hox and c-myc expression (shown in white) and physically interacts with Brgl and Smarcd3, while it may bind to the Oct4 and Gmnn genomic loci (shown in green). RAR and Brm are postulated to induce chromatin remodeling and inhibit Nanog and Oct4 expression, upon RA induction, while RAR also modulates Hox gene expression, possibly in co-operation with Brg1. Gmnn regulates Hox expression (shown in white), interacts with Hox and Brgl proteins and shares bidirectional inhibition with the Wnt signaling pathway (shown in red). HNF4 is predicted to bind to Oct4 and Gmnn sequences (shown in green), while COUP-TF is known to inhibit Oct4 (shown in red) and is predicted to bind to Gmnn (shown in green). Oct4 inhibits COUP-TFII (shown in red) and induces expression of mir-302 (shown in blue), which in turn, inhibits COUPT-TFII (shown in red).

Moreover, RA has been shown to repress canonical and activate the non-canonical Wnt pathway in ES cells (44) and, in line with this, there is evidence that geminin expression is also regulated by Wnt. More specifically, geminin 5' regulatory sequences and endogenous geminin positively feedbacked to exogenous Wnt signals in Xenopus laevis embryos (45) while geminin down-regulation was shown to enhance Wnt signaling (46). This complex signaling cascade is summarized in Figure 1.

Evidence for Oct4 and geminin regulation by HNF4 and COUPTF. The results of the present study predict that, Oct4 and geminin, apart from RAR, have common binding sequences for HNF4 ( $p=0.016$; g:SCS algorithm) and COUPTF ( $p=0.0266$; 


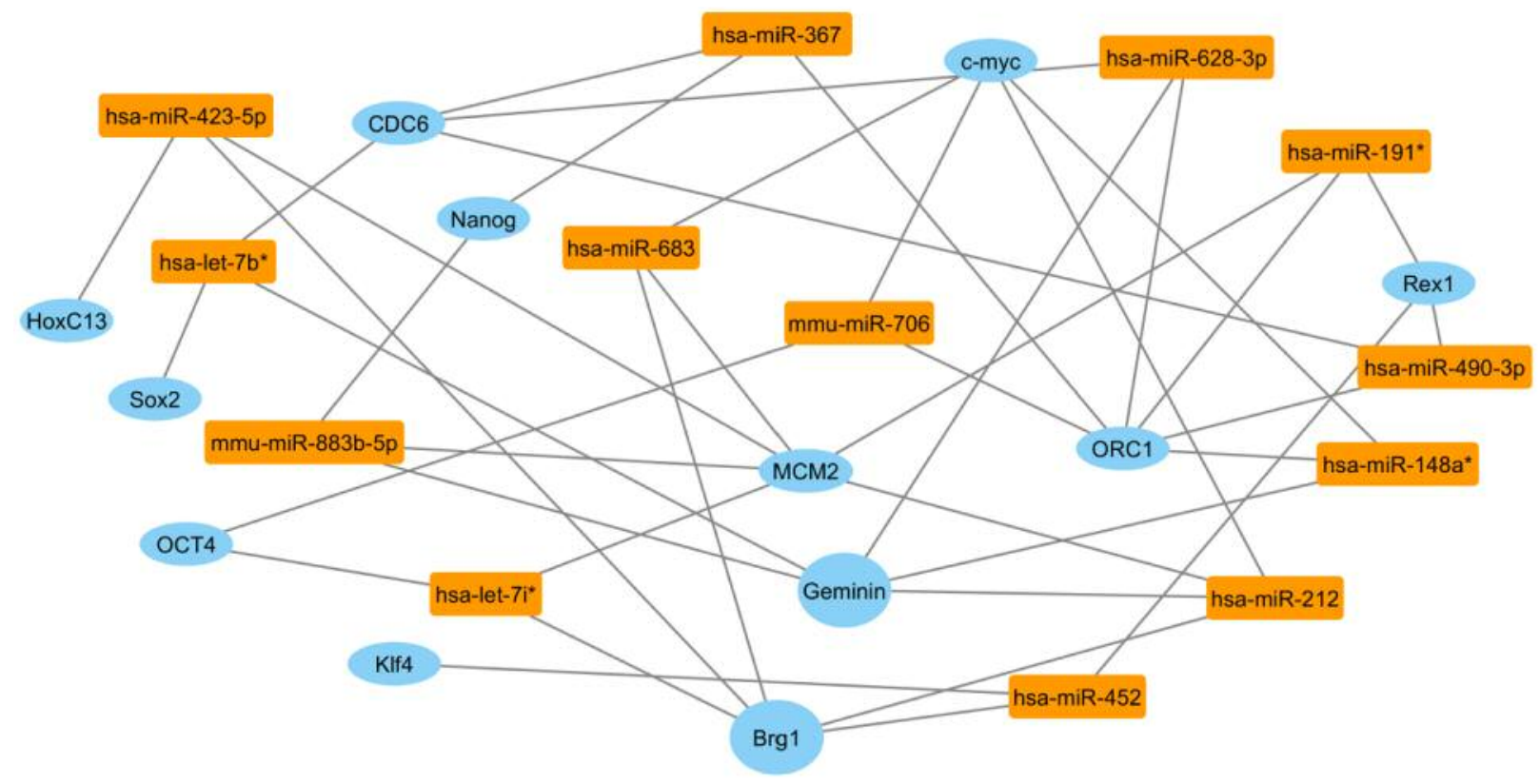

Figure 2. Network of miRNA UTR binding targets, predicted using miRBase. miRNAs are depicted in yellow and genomic UTRs in blue. Network representation was generated by Cytoscape (version 3.3.0, USA). Node distances in the network are not to scale.

g:SCS algorithm). Common regulation of Oct4 and geminin by HNF4 seems to be in line with the recent finding that geminin together with the GATA6 TF can induce the generation of induced-pluripotent stem cells (iPSCs), without the need for Oct4 and Sox2 expression (47). Interestingly, our previous RNA-seq has shown that upon geminin ablation, HNF4a is highly up-regulated in the fetal liver (36).

Additionally, there is experimental evidence that COUP$\mathrm{TF}$ is a ligand-activated nuclear receptor, with RA as a ligand (48), while other studies had shown that this receptor serves as a RAR accessory protein (49) and is involved in RA signaling (50-52). Interestingly, a regulatory network has also been identified, involving the miRNA miR-302 and the TFs OCT4 and COUPTFII (53) (Figure 1).

\section{Geminin, miRNAs, GABA signaling and retinoic acid}

Recent data have revealed an important role for miRNAs in pluripotency as well as regulation of the cell cycle. miRNAs can maintain the pluripotency state (54) or facilitate an exit, by repressing core pluripotency factors $(55,56)$. There is also increasing evidence about their role in the cell cycle and replicative stress $(57,58)$. It has been shown, for example, that the miR-34 family targets the MCM proteins of the preRC complex (59-61).

Geminin and mir-452. Geminin has only recently been reported to be targeted by miR-571, the only miRNA known to date to prevent aberrant DNA replication (62). Besides MiR-571, no other miRNA has been reported to target geminin or any pre-RC component associated with the previously described circuitry. Nevertheless, geminin appears to share a spatiotemporal expression pattern with mir-452.

Firstly, this miRNA is enriched during mouse neural crest development where it plays a role in the epithelialmesenchymal signaling; mir-452 down-regulation affects the Sonic hedgehog and Fgf8 signaling in the first branchial arch, through Wnt5a down-regulation, resulting in craniofacial defects (63). Similarly, a study by Emmett and O'Shea has shown that geminin knockdown resulted in E9.5 embryos with smaller and abnormally oriented first branchial arch with reduced $F g f 8$ expression (64). In line with this, our previous results have shown that mice lacking geminin expression have a reduced number of neural crest cells at E9.5 and 10.5 (65). Another study has reported similar results by E10.5 (66), whereas, in a reciprocal approach, FGF8 has been reported to induce geminin expression (30). Geminin down-regulation has also been reported to up-regulate Wnt5a in the primitive streak (46) and has been associated to the epithelial-mesenchymal transition (EMT), even though there is conflicting evidence as to whether its down-regulation (46) or overexpression $(64,67)$ promotes EMT.

Secondly, mir-452 overexpression has been reported to down-regulate the pluripotency regulators Klf4, Sox2, Oct4, Nanog and c-Myc as well as Bmi1, LEF1 and TCF4 in 
glioma cells (68). In hepatocellular carcinoma cells (HCC), mir-452 directly targeted Sox7, which has been shown to interact with TCF4. HCC treatment with all-trans retinoic acid (ATRA) promoted cell differentiation and apoptosis and suppressed metastasis in mouse models (69). Regarding geminin, as already mentioned, its expression is required for maintaining Oct4, Sox 2 and Nanog expression in ES cells $(19,29)$, while the geminin promoter contains binding sites for the TCF transcription factor (45). In addition, Caronna et $a l$. have reported that geminin directly binds and represses the Lef1 promoter (46).

Thirdly, E2F1 directly activates mir-452 by transactivating its host gene, GABAA receptor $\varepsilon$, in melanoma cell lines. In turn, mir-452 induces EMT and down-regulates TXNIP, a metastasis suppressor (70). Similarly, TXNIP expression induces p27 (71) which promotes EMT via Twist1 upregulation (72). Surprisingly, the geminin promoter has E2Fresponsive sequences and E2F1-4 have been shown to upregulate geminin (10) while geminin dysregulation is associated with increased Twist1 $(46,67)$.

GABA signaling, geminin and $H 2 A X$. As mentioned above, E2F1 can activate GABAA receptor $\varepsilon$, which in turn induces mir-452 expression (70). Interestingly, signaling through GABAA receptors has been reported to be mediated through $\mathrm{H} 2 \mathrm{AX}$ and inhibit the proliferation of ES cell and neural crest stem cells, independently of differentiation or DNA damage (73). Similarly, H2AX phosphorylation through GABAA activation negatively regulates proliferation of neural stem cells in the subventricular zone (74). $\gamma \mathrm{H} 2 \mathrm{AX}$ is well-known to be induced upon geminin down-regulation, as a result of rereplication and DNA damage $(75,76)$. However, it is plausible that geminin-induced $\gamma \mathrm{H} 2 \mathrm{AX}$ can also affect cell proliferation. So far, geminin is known to affect proliferation-differentiation decisions through different factors (77-82) but not H2AX. Nevertheless, inactivation of geminin at E3.5 has been shown to be lethal due to proliferation defects concurrently with an increase in $\gamma \mathrm{H} 2 \mathrm{AX}$ (83).

Retinoic acid, pluripotency and cell cycle miRNA regulation. In order to identify mRNA UTR binding targets of miRNAs, an in silico analysis was carried out using g:Profiler $(23,24)$, employing the miRBase database (28). This analysis identified several miRNAs that were predicted to bind to UTRs of cell cycle and pluripotency factors, pointing to a common regulatory mechanism. Within this miRNA network, cell cycle factors i.e. geminin, MCM2, ORC1 and CDC6 are predicted to be coregulated with pluripotency factors Nanog, Oct4, Sox2 and $\operatorname{Rex} 1$, as well as $\operatorname{Brg} 1$, $\operatorname{HoxC} 13$ and Klf4. More specifically, mmu-miR-883b-5p is predicted to bind to Nanog as well as geminin and $\mathrm{Mcm} 2$. According to similar predictions, mmu-miR-706 binds to Oct4, Orc1 and c-myc. hsa-miR-367 binds to Nanog as well as Cdc6 and Orc1. hsa-
miR-490-3p binds to Rex1 as well as CDC6 and ORC1. hsamiR-148a* binds to c-myc, geminin and ORC1. hsa-miR-212 binds to Brg1, geminin, Mcm2 and c-myc. hsa-let-7b* binds to Sox2, geminin and CDC6. hsa-miR-423-5p binds to HoxC13, Brg1 and Mcm2. hsa-miR-452 binds to Klf4, Brg1 and Rex1. All the above including some further predictions are graphed as a network in Figure 2.

Several of these miRNAs have been experimentally reported to be modulated by retinoic acid. let-7b, predicted to bind to Sox2, geminin and CDC6 UTRs, has been found to be up-regulated in response to all-trans retinoic acid treatment of the NB4 cells, a human acute promyelocytic leukemia cell line (84). Similarly, miR-883b-5p, predicted to bind to Nanog, MCM2 and geminin UTRs, has been found to be highly up-regulated in J1 mouse ES cells upon RAinduced differentiation (85), while miR-423, predicted to bind to HoxC13, Brg1 and MCM2 was up-regulated in the neuroblast-like SH-SY5Y cells, again, upon RA induction (86). In the latter cell line, RA has also been reported to upregulate miR-628-3p (predicted to bind to the UTRs of geminin, ORC1 and CDC6) and down-regulate miR-490-3p (predicted to bind to CDC6, ORC1 and Rex1) (87).

\section{Conclusion}

Based on the results of the present study, along with extensive evidence from the literature, it is evident that there is a circuitry between RA signaling, SWI/SNF, pluripotency factors and cell-cycle regulators. The role of geminin in this circuitry is shown to be of great significance.

While being essential for the maintenance of genome stability, we have previously shown that geminin acts as a tumor suppressor in the murine colon and lung cancer model (4). In addition, it is frequently overexpressed in several human cancers and a recent study has shown that geminin overexpression promotes breast cancer metastasis through FoxO3 deacetylation (88). Geminin is, therefore, involved in cancer, development and pluripotency. It has also recently been reported to be targeted by miR-571, the first miRNA to prevent aberrant DNA replication (62).

Further transcriptional and miRNA interactions could be examined by molecular dynamic simulations (89-92) and verified in vitro by chromatin immunoprecipitation, miRNA/ mRNA co-expression and the study of miRNA effects on target proteins (93), along with analysis of possible epigenetic changes. A better understanding of this crosstalk will be invaluable for delineating the cell-cycle links to the loss of pluripotency, subsequent cell differentiation and oncogenesis.

\section{Conflicts of Interest}

The Authors declare no conflicts of interest regarding this study. 


\section{Authors' Contributions}

SCT and ST designed the study and SCT wrote the paper. GJD and MP wrote portions of the paper. SCT and DV performed the bioinformatic analysis. SCT, GJD, VB, GTS and ST analyzed the data relating to transcription factor binding sites. SCT, AP, AKA, MV and GTS analyzed the data relating to miRNA interactions. All authors critically reviewed the final version of the paper.

\section{Acknowledgements}

This article was funded by the "THALES: The role and mechanisms of asymmetric cell division during stem cell differentiation" program, which is co-financed by the European Social Fund (ESF) and Greek National Funds through the Operational Program "Education and Lifelong Learning" of the National Strategic Reference Framework (NSFR).

\section{References}

1 Symeonidou IE, Kotsantis P, Roukos V, Rapsomaniki MA, Grecco HE, Bastiaens P, Taraviras S and Lygerou Z: Multi-step loading of human minichromosome maintenance proteins in live human cells. J Biol Chem 288: 35852-35867, 2013. PMID: 24158436. DOI: 10.1074/jbc.M113.474825

2 Fragkos M, Ganier O, Coulombe P and Méchali M: DNA replication origin activation in space and time. Nat Rev Mol Cell Biol 16: 360-374, 2015. PMID: 25999062. DOI: 10.1038/ nrm4002

3 Petropoulos M, Champeris Tsaniras S, Taraviras S and Lygerou Z: Replication licensing aberrations, replication stress, and genomic instability. Trends Biochem Sci 44(9): 752-764, 2019. PMID: 31054805. DOI: 10.1016/j.tibs.2019.03.011

4 Champeris Tsaniras S, Villiou M, Giannou AD, Nikou S, Petropoulos M, Pateras IS, Tserou P, Karousi F, Lalioti ME, Gorgoulis VG, Patmanidi AL, Stathopoulos GT, Bravou V, Lygerou $\mathrm{Z}$ and Taraviras S: Geminin ablation in vivo enhances tumorigenesis through increased genomic instability. J Pathol 246: 134-140, 2018. PMID: 29952003. DOI: 10.1002/path.5128

5 Gorgoulis VG, Vassiliou LVF, Karakaidos P, Zacharatos P, Kotsinas A, Liloglou T, Venere M, DiTullio RA, Kastrinakis NG, Levy B, Kletsas D, Yoneta A, Herlyn M, Kittas C and Halazonetis TD: Activation of the DNA damage checkpoint and genomic instability in human precancerous lesions. Nature 434: 907-913, 2005. PMID: 15829965. DOI: 10.1038/nature03485

6 Montanari M, Macaluso A, Cittadini A and Giordano A: Role of geminin: from normal control of DNA replication to cancer formation and progression? Cell Death Differ 13: 1052-1056, 2006. PMID: 16628231. DOI: 10.1038/sj.cdd.4401932

7 Petropoulou C, Kotantaki P, Karamitros D and Taraviras S: Cdt1 and Geminin in cancer: markers or triggers of malignant transformation? Front Biosci 13: 4485-4494, 2008. PMID: 18508524. DOI: $10.2741 / 3018$

8 McGarry T and Kirschner M: Geminin, an inhibitor of DNA replication, is degraded during mitosis. Cell 93: 1043-1053, 1998. PMID: 9635433. DOI: 10.1016/s0092-8674(00)81209-x

9 Ohno Y, Saeki K, Yasunaga S, Kurogi T, Suzuki-Takedachi K, Shirai M, Mihara K, Yoshida K, Voncken J, Ohtsubo M and Takihara Y: Transcription of the Geminin gene is regulated by a negative-feedback loop. Mol Biol Cell 25: 1374-1383, 2014. PMID: 24554762. DOI: 10.1091/mbc.E13-09-0534

10 Yoshida $\mathrm{K}$ and Inoue I: Regulation of Geminin and Cdt1 expression by E2F transcription factors. Oncogene 23: 38023812, 2004. PMID: 14990995. DOI: 10.1038/sj.onc.1207488

11 Bravou V, Nishitani H, Song SY, Taraviras S and Varakis J: Expression of the licensing factors, Cdt1 and Geminin, in human colon cancer. Int J Oncol 27: 1511-1518, 2005. PMID: 16273206.

12 Blanchard Z, Malik R, Mullins N, Maric C, Luk H, Horio D, Hernandez B, Killeen $J$ and ElShamy WM: Geminin overexpression induces mammary tumors via suppressing cytokinesis. Oncotarget 2: 1011-1027, 2011. PMID: 22184288. DOI: 10.18632 /oncotarget.363

13 Siril Y, Kouketsu A, Oikawa M, Takahashi T and Kumamoto H: Immunohistochemical assessment of chromatin licensing and DNA replication factor 1 , geminin, and $\gamma-\mathrm{H} 2 \mathrm{~A} . \mathrm{X}$ in oral epithelial precursor lesions and squamous cell carcinoma. J Oral Pathol Med, 2019. PMID: 31318980. DOI: 10.1111/jop.12925

14 Champeris Tsaniras S, Kanellakis N, Symeonidou IE, Nikolopoulou P, Lygerou Z and Taraviras S: Licensing of DNA replication, cancer, pluripotency and differentiation: An interlinked world? Semin Cell Dev Biol 30: 174-180, 2014. PMID: 24641889. DOI: 10.1016/j.semcdb.2014.03.013

15 Champeris Tsaniras S, Vlachakis D and Taraviras S: The Nucleophosmin-Pin1 interaction links the cell cycle, cancer and pluripotency. J Mol Biochem 4: 50-51, 2015.

16 Patmanidi AL, Champeris Tsaniras S, Karamitros D, Kyrousi C, Lygerou Z and Taraviras S: Concise review: Geminin-A tale of two tails: DNA replication and transcriptional/epigenetic regulation in stem cells. Stem Cells 35: 299-310, 2017. PMID: 27859962. DOI: $10.1002 /$ stem.2529

17 Kroll K, Salic A, Evans L and Kirschner M: Geminin, a neuralizing molecule that demarcates the future neural plate at the onset of gastrulation. Development 125: 3247-3258, 1998. PMID: 9671596.

18 Luo L, Yang X, Takihara Y, Knoetgen H and Kessel M: The cellcycle regulator geminin inhibits Hox function through direct and polycomb-mediated interactions. Nature 427: 749-753, 2004. PMID: 14973489. DOI: 10.1038/nature02305

19 Tabrizi GA, Böse K, Reimann Y and Kessel M: Geminin is required for the maintenance of pluripotency. PLoS One 8: e73826, 2013. PMID: 24069236. DOI: 10.1371/journal.pone.0073826

20 Zhao X, Ji J, Yu L-R, Veenstra T and Wang XW: Cell cycledependent phosphorylation of nucleophosmin and its potential regulation by peptidyl-prolyl cis/trans isomerase. $\mathrm{J}$ Mol Biochem 4: 95-103, 2015. PMID: 27099843.

21 Kareta MS, Sage J and Wernig M: Crosstalk between stem cell and cell cycle machineries. Curr Opin Cell Biol 37: 68-74, 2015. PMID: 26520682. DOI: 10.1016/j.ceb.2015.10.001

22 Gonzales KAU, Liang H, Lim YS, Chan YS, Yeo JC, Tan CP, Gao B, Le B, Tan ZY, Low KY, Liou YC, Bard F and Ng HH: Deterministic restriction on pluripotent state dissolution by cellcycle pathways. Cell 162: 564-579, 2015. PMID: 26232226. DOI: $10.1016 /$ j.cell.2015.07.001

23 Reimand J, Kull M, Peterson H, Hansen J and Vilo J: g:Profiler-a web-based toolset for functional profiling of gene lists from large-scale experiments. Nucleic Acids Res 35: W193-200, 2007. PMID: 17478515 . DOI: $10.1093 / \mathrm{nar} / \mathrm{gkm} 226$

24 Reimand J, Arak T and Vilo J: g:Profiler - a web server for functional interpretation of gene lists (2011 update). Nucleic 
Acids Res 39: W307-315, 2011. PMID: 21646343. DOI: 10.1093/nar/gkr378

25 Raudvere U, Kolberg L, Kuzmin I, Arak T, Adler P, Peterson H and Vilo J: g:Profiler: a web server for functional enrichment analysis and conversions of gene lists (2019 update). Nucleic Acids Res 47: W191-W198, 2019. PMID: 31066453. DOI: $10.1093 / \mathrm{nar} / \mathrm{gkz} 369$

26 Matys V, Kel-Margoulis O V, Fricke E, Liebich I, Land S, BarreDirrie A, Reuter I, Chekmenev D, Krull M, Hornischer K, Voss N, Stegmaier P, Lewicki-Potapov B, Saxel H, Kel AE and Wingender E: TRANSFAC and its module TRANSCompel: transcriptional gene regulation in eukaryotes. Nucleic Acids Res 34: D108-110, 2006. PMID: 16381825. DOI: 10.1093/nar/gkj143

27 Oughtred R, Stark C, Breitkreutz B-J, Rust J, Boucher L, Chang C, Kolas N, O’Donnell L, Leung G, McAdam R, Zhang F, Dolma S, Willems A, Coulombe-Huntington J, Chatr-Aryamontri A, Dolinski K and Tyers M: The BioGRID interaction database: 2019 update. Nucleic Acids Res 47: D529-D541, 2019. PMID: 30476227. DOI: 10.1093/nar/gky 1079

28 Griffiths-Jones S, Saini HK, Van Dongen S and Enright AJ: miRBase: Tools for microRNA genomics. Nucleic Acids Res 36, 2008. PMID: 17991681. DOI: 10.1093/nar/gkm952

29 Yang V, Carter S, Hyland S, Tachibana-Konwalski K, Laskey R and Gonzalez M: Geminin escapes degradation in G1 of mouse pluripotent cells and mediates the expression of Oct4, Sox2, and Nanog. Curr Biol 21: 692-699, 2011. PMID: 21497086. DOI: 10.1016/j.cub.2011.03.026

30 Papanayotou C, Mey A, Birot AM, Saka Y, Boast S, Smith JC, Samarut $J$ and Stern CD: A mechanism regulating the onset of Sox2 expression in the embryonic neural plate. PLoS Biol 6: 01090123, 2008. PMID: 18184035. DOI: 10.1371/journal.pbio.0060002

31 Janesick A, Abbey R, Chung C, Liu S, Taketani M and Blumberg B: ERF and ETV3L are retinoic acid-inducible repressors required for primary neurogenesis. Development 140 3095-106, 2013. PMID: 23824578. DOI: 10.1242/dev.093716

32 Gutierrez-Mazariegos J, Schubert M and Laudet V: Evolution of retinoic acid receptors and retinoic acid signaling. Subcell Biochem 70: 55-73, 2014. PMID: 24962881. DOI: 10.1007/97894-017-9050-5_4

33 Okazawa H, Okamoto K, Ishino F, Ishino-Kaneko T, Takeda S, Toyoda Y, Muramatsu M and Hamada $\mathrm{H}$ : The oct 3 gene, a gene for an embryonic transcription factor, is controlled by a retinoic acid repressible enhancer. EMBO J 10: 2997-3005, 1991. PMID: 1915274

34 Schoorlemmer J, van Puijenbroek A, van Den Eijnden M, Jonk L, Pals $\mathrm{C}$ and Kruijer W: Characterization of a negative retinoic acid response element in the murine Oct4 promoter. Mol Cell Biol 14: 1122-1136, 1994. PMID: 8289793. DOI: 10.1128/mcb.14.2.1122

35 Hoemme C, Peerzada A, Behre G, Wang Y, McClelland M, Nieselt K, Zschunke M, Disselhoff C, Agrawal S, Isken F, Tidow N, Berdel WE, Serve $\mathrm{H}$ and Müller-Tidow C: Chromatin modifications induced by PML-RAR \{alpha\} repress critical targets in leukemogenesis as analyzed by ChIP-chip. Blood 111: 2887-2895, 2008. PMID: 18024792. DOI: 10.1182/blood-2007-03-079921

36 Karamitros D, Patmanidi AL, Kotantaki P, Potocnik AJ, BährIvacevic T, Benes V, Lygerou Z, Kioussis D and Taraviras S: Geminin deletion increases the number of fetal hematopoietic stem cells by affecting the expression of key transcription factors. Development 142: 70-81, 2015. PMID: 25516969. DOI: $10.1242 /$ dev. 109454
37 Patmanidi AL, Kanellakis NI, Karamitros D, Papadimitriou C, Lygerou $\mathrm{Z}$ and Taraviras S: Whole transcriptome data analysis of mouse embryonic hematopoietic stem and progenitor cells that lack Geminin expression. Data Br 7: 889-893, 2016. PMID: 27077091. DOI: 10.1016/j.dib.2016.03.028

$38 \mathrm{Wu} \mathrm{C}-\mathrm{Y}$, Feng $\mathrm{X}$ and Wei L-N: Coordinated repressive chromatin-remodeling of Oct4 and Nanog genes in RA-induced differentiation of embryonic stem cells involves RIP140. Nucleic Acids Res 42: 4306-4317, 2014. PMID: 24489122. DOI: 10.1093/nar/gku092

39 Flajollet S, Lefebvre B, Cudejko C, Staels B and Lefebvre P: The core component of the mammalian SWI/SNF complex SMARCD3/BAF60c is a coactivator for the nuclear retinoic acid receptor. Mol Cell Endocrinol 270: 23-32, 2007. PMID: 17363140. DOI: 10.1016/j.mce.2007.02.004

40 Roukos V, Iliou MS, Nishitani H, Gentzel M, Wilm M, Taraviras $\mathrm{S}$ and Lygerou Z: Geminin cleavage during apoptosis by caspase-3 alters its binding ability to the SWI/SNF subunit Brahma. J Biol Chem 282: 9346-9357, 2007. PMID: 17261582. DOI: $10.1074 /$ jbc.M611643200

41 Seo S, Herr A, Lim J-W, Richardson GA, Richardson H and Kroll KL: Geminin regulates neuronal differentiation by antagonizing Brg1 activity. Genes Dev 19: 1723-1734, 2005. PMID: 16024661. DOI: 10.1101/gad.1319105

42 Carey T, Cao Z, Choi I, Ganguly A, Wilson C, Paul S and Knott J: BRG1 Governs Nanog Transcription in Early Mouse Embryos and Embryonic Stem Cells via Antagonism of Histone H3 Lysine 9/14 Acetylation. Mol Cell Biol 35: 4158-4169, 2015. PMID: 26416882. DOI: 10.1128/MCB.00546-15

43 Kidder B, Palmer S and Knott J: SWI/SNF-Brg1 regulates selfrenewal and occupies core pluripotency-related genes in embryonic stem cells. Stem Cells 27: 317-328, 2009. PMID: 19056910. DOI: 10.1634/stemcells.2008-0710

44 Champeris Tsaniras S: Generating Mature $\beta$-Cells From Embryonic Stem Cells. Strategies for Late-Stage Differentiation. In: Vitamins and Hormones. Academic Press Inc., pp 79-92, 2011. PMID: 22127238. DOI: 10.1016/B978-0-12-3860156.00025-1

45 Taylor JJ, Wang T and Kroll KL: Tcf- and Vent-binding sites regulate neural-specific geminin expression in the gastrula embryo. Dev Biol 289: 494-506, 2006. PMID: 16337935. DOI: 10.1016/j.ydbio.2005.10.047

46 Caronna EA, Patterson ES, Hummert PM and Kroll KL: Geminin restrains mesendodermal fate acquisition of embryonic stem cells and is associated with antagonism of Wnt signaling and enhanced polycomb-mediated repression. Stem Cells 31: 1477-1487, 2013. PMID: 23630199. DOI: 10.1002/stem.1410

47 Shu J, Wu C, Wu Y, Li Z, Shao S, Zhao W, Tang X, Yang H, Shen L, Zuo X, Yang W, Shi Y, Chi X, Zhang H, Gao G, Shu Y, Yuan $\mathrm{K}, \mathrm{He} \mathrm{W}$, Tang C, Zhao Y and Deng H: Induction of pluripotency in mouse somatic cells with lineage specifiers. Cell 153: 963-975, 2013. PMID: 23706735. DOI: 10.1016/j.cell.2013.05.001

48 Kruse SW, Suino-Powell K, Zhou XE, Kretschman JE, Reynolds R, Vonrhein C, Xu Y, Wang L, Tsai SY, Tsai M-J and Xu HE: Identification of COUP-TFII orphan nuclear receptor as a retinoic acid-activated receptor. PLoS Biol 6: e227, 2008. PMID: 18798693. DOI: 10.1371/journal.pbio.0060227

49 Lin B, Chen GQ, Xiao D, Kolluri SK, Cao X, Su H and Zhang $\mathrm{XK}$ : Orphan receptor COUP-TF is required for induction of retinoic acid receptor beta, growth inhibition, and apoptosis by 
retinoic acid in cancer cells. Mol Cell Biol 20: 957-970, 2000 PMID: 10629053. DOI: $10.1128 / \mathrm{mcb} \cdot 20.3 .957-970.2000$

50 Kliewer SA, Umesono K, Heyman RA, Mangelsdorf DJ, Dyck JA and Evans RM: Retinoid X receptor-COUP-TF interactions modulate retinoic acid signaling. Proc Natl Acad Sci USA 89: 1448-1452, 1992. PMID: 1311101. DOI: 10.1073/pnas.89.4.1448

51 Pickens BS, Teets BW, Soprano KJ and Soprano DR: Role of COUP-TFI during retinoic acid-induced differentiation of P19 cells to endodermal cells. J Cell Physiol 228: 791-800, 2013. PMID: 23018522. DOI: $10.1002 /$ jcp. 24228

52 Love CE and Prince VE: Expression and retinoic acid regulation of the zebrafish nr2f orphan nuclear receptor genes. Dev Dyn 241: 1603-1615, 2012. PMID: 22836912. DOI: 10.1002/dvdy.23838

53 Rosa A and Brivanlou AH: A regulatory circuitry comprised of miR-302 and the transcription factors OCT4 and NR2F2 regulates human embryonic stem cell differentiation. EMBO J 30: 237-248, 2011. PMID: 21151097. DOI: 10.1038/emboj.2010.319

54 Lüningschrör P, Stöcker B, Kaltschmidt B and Kaltschmidt C: miR-290 cluster modulates pluripotency by repressing canonical NF- $x$ B signaling. Stem Cells 30: 655-664, 2012. PMID: 22232084. DOI: $10.1002 /$ stem.1033

55 Anokye-Danso F, Trivedi CM, Juhr D, Gupta M, Cui Z, Tian Y, Zhang Y, Yang W, Gruber PJ, Epstein JA and Morrisey EE: Highly efficient miRNA-mediated reprogramming of mouse and human somatic cells to pluripotency. Cell Stem Cell 8: 376-388, 2011. PMID: 21474102. DOI: 10.1016/j.stem.2011.03.001

56 Xu N, Papagiannakopoulos T, Pan G, Thomson JA and Kosik KS: MicroRNA-145 Regulates OCT4, SOX2, and KLF4 and Represses Pluripotency in Human Embryonic Stem Cells. Cell 137: 647-658, 2009. PMID: 19409607. DOI: 10.1016/j.cell.2009.02.038

57 Bueno MJ and Malumbres M: MicroRNAs and the cell cycle. Biochim Biophys Acta - Mol Basis Dis 1812: 592-601, 2011. PMID: 21315819. DOI: 10.1016/j.bbadis.2011.02.002

58 Wan G, Mathur R, Hu X, Zhang X and Lu X: MiRNA response to DNA damage. Trends Biochem Sci 36: 478-484, 2011. PMID: 21741842. DOI: $10.1016 /$ j.tibs.2011.06.002

59 Chuang $\mathrm{CH}$, Yang D, Bai G, Freeland A, Pruitt SC and Schimenti JC: Post-transcriptional homeostasis and regulation of MCM2-7 in mammalian cells. Nucleic Acids Res 40: 4914-4924, 2012. PMID: 22362746. DOI: $10.1093 / \mathrm{nar} / \mathrm{gks} 176$

60 Kaller M, Liffers S-T, Oeljeklaus S, Kuhlmann K, Röh S, Hoffmann R, Warscheid B and Hermeking H: Genome-wide characterization of miR-34a induced changes in protein and mRNA expression by a combined pulsed SILAC and microarray analysis. Mol Cell Proteomics 10: M111.010462, 2011. PMID: 21566225. DOI: 10.1074/mcp.M111.010462

61 Lal A, Thomas MP, Altschuler G, Navarro F, O’Day E, Li XL, Concepcion C, Han Y-C, Thiery J, Rajani DK, Deutsch A, Hofmann $\mathrm{O}$, Ventura A, Hide $\mathrm{W}$ and Lieberman J: Capture of microRNAbound mRNAs identifies the tumor suppressor miR-34a as a regulator of growth factor signaling. PLoS Genet 7: e1002363, 2011. PMID: 22102825. DOI: 10.1371/journal.pgen.1002363

62 Zhang Y, Li Z, Hao Q, Tan W, Sun J, Li J, Chen C, Li Z, Meng Y, Zhou Y, Han Z, Pei H, DePamphilis M and Zhu W: The Cdk2-c-Myc-miR-571 Axis Regulates DNA Replication and Genomic Stability by Targeting Geminin. Cancer Res 79: 48964910, 2019. PMID: 31431461. DOI: 10.1158/0008-5472.CAN19-0020

63 Sheehy NT, Cordes KR, White MP, Ivey KN and Srivastava D: The neural crest-enriched microRNA miR-452 regulates epithelial-mesenchymal signaling in the first pharyngeal arch. Development 137: 4307-4316, 2010. PMID: 21098571. DOI: 10.1242/dev.052647

64 Emmett LSD and O'Shea KS: Geminin is required for epithelial to mesenchymal transition at gastrulation. Stem Cells Dev 21: 2395-2409, 2012. PMID: 22335560. DOI: 10.1089/scd. 2011.0483

65 Stathopoulou A, Natarajan D, Nikolopoulou P, Patmanidi AL, Lygerou Z, Pachnis V and Taraviras S: Inactivation of Geminin in neural crest cells affects the generation and maintenance of enteric progenitor cells, leading to enteric aganglionosis. Dev Biol 409: 392-405, 2016. PMID: 26658318. DOI: 10.1016/ j.ydbio.2015.11.023

66 Patterson ES, Waller LE and Kroll KL: Geminin loss causes neural tube defects through disrupted progenitor specification and neuronal differentiation. Dev Biol 393: 44-56, 2014. PMID: 24995796. DOI: $10.1016 /$ j.ydbio.2014.06.021

67 Slawny N and O'Shea KS: Geminin promotes an epithelial-tomesenchymal transition in an embryonic stem cell model of gastrulation. Stem Cells Dev 22: 1177-1189, 2013. PMID: 23249188. DOI: $10.1089 / \mathrm{scd} .2012 .0050$

68 Liu L, Chen K, Wu J, Shi L, Hu B, Cheng S, Li M and Song L: Downregulation of miR-452 promotes stem-like traits and tumorigenicity of gliomas. Clin Cancer Res 19: 3429-3438, 2013. PMID: 23695168. DOI: 10.1158/1078-0432.CCR-12-3794

69 Zheng Z, Liu J, Yang Z, Wu L, Xie H, Jiang C, Lin B, Chen T, Xing C, Liu Z, Song P, Yin S, Zheng S and Zhou L: MicroRNA452 promotes stem-like cells of hepatocellular carcinoma by inhibiting sox7 involving wnt/ $\beta$-catenin signaling pathway. Oncotarget 7: 28000-28012, 2016. PMID: 27058905. DOI: 10.18632/oncotarget.8584

70 Knoll S, Fürst K, Kowtharapu B, Schmitz U, Marquardt S, Wolkenhauer O, Martin H and Pützer BM: E2F1 induces miR224/452 expression to drive EMT through TXNIP downregulation. EMBO Rep 15: 1315-1329, 2014. PMID: 25341426. DOI: 10.15252/embr.201439392

71 Nie W, Huang W, Zhang W, Xu J, Song W, Wang Y, Zhu A, Luo J, Huang G, Wang Y and Guan X: TXNIP interaction with the Her-1/2 pathway contributes to overall survival in breast cancer. Oncotarget 6: 3003-3012, 2015. PMID: 25605021. DOI: 10.18632/oncotarget.3096

72 Zhao D, Besser AH, Wander SA, Sun J, Zhou W, Wang B, Ince T, Durante MA, Guo W, Mills G, Theodorescu D and Slingerland J: Cytoplasmic p27 promotes epithelialmesenchymal transition and tumor metastasis via STAT3mediated Twist1 upregulation. Oncogene 34: 5447-5459, 2015. PMID: 25684140. DOI: 10.1038/onc.2014.473

73 Andäng M, Hjerling-Leffler J, Moliner A, Lundgren TK, CasteloBranco G, Nanou E, Pozas E, Bryja V, Halliez S, Nishimaru H, Wilbertz J, Arenas E, Koltzenburg M, Charnay P, Manira A El, Ibañez CF and Ernfors P: Histone H2AX-dependent GABAA receptor regulation of stem cell proliferation. Nature 451: 460464, 2008. PMID: 18185516. DOI: 10.1038/nature06488

74 Fernando RN, Eleuteri B, Abdelhady S, Nussenzweig A, Andäng $\mathrm{M}$ and Ernfors P: Cell cycle restriction by histone H2AX limits proliferation of adult neural stem cells. Proc Natl Acad Sci USA 108: 5837-5842, 2011. PMID: 21436033. DOI: 10.1073/pnas. 1014993108

75 Melixetian M, Ballabeni A, Masiero L, Gasparini P, Zamponi R, Bartek J, Lukas $\mathrm{J}$ and Helin $\mathrm{K}$ : Loss of Geminin induces 
rereplication in the presence of functional p53. J Cell Biol 165: 473-482, 2004. PMID: 15159417. DOI: 10.1083/jcb.200403106

$76 \mathrm{Zhu}$ W, Chen Y and Dutta A: Rereplication by depletion of geminin is seen regardless of p53 status and activates a $G_{2} / M$ checkpoint. Mol Cell Biol 24: 7140-7150, 2004. PMID: 15282313. DOI: 10.1128/MCB.24.16.7140-7150.2004

77 Barry KA, Schultz KM, Payne CJ and McGarry TJ: Geminin is required for mitotic proliferation of spermatogonia. Dev Biol 371: 35-46, 2012. PMID: 22898305. DOI: 10.1016/j.ydbio.2012.07.031

78 de Renty C, Kaneko KJ and DePamphilis ML: The dual roles of geminin during trophoblast proliferation and differentiation. Dev Biol 387: 49-63, 2014. PMID: 24412371. DOI: 10.1016/ j.ydbio.2013.12.034

79 Karamitros D, Kotantaki P, Lygerou Z, Veiga-Fernandes H, Pachnis V, Kioussis D and Taraviras S: Differential geminin requirement for proliferation of thymocytes and mature $\mathrm{T}$ cells. J Immunol 184: 2432-2441, 2010. PMID: 20107189. DOI: 10.4049/jimmunol.0901983

80 Karamitros D, Kotantaki P, Lygerou Z, Veiga-Fernandes H, Pachnis V, Kioussis D and Taraviras S: Life without geminin. Cell Cycle 9: 3181-3185, 2010. PMID: 20697201. DOI: 10.4161/cc.9.16.12554

81 Karamitros D, Kotantaki P, Lygerou Z, Kioussis D and Taraviras S: T cell proliferation and homeostasis: an emerging role for the cell cycle inhibitor geminin. Crit Rev Immunol 31: 209-331, 2011. PMID: 21740351.

82 Spella M, Kyrousi C, Kritikou E, Stathopoulou A, Guillemot F, Kioussis D, Pachnis V, Lygerou Z and Taraviras S: Geminin regulates cortical progenitor proliferation and differentiation. Stem Cells 29: 1269-1282, 2011. PMID: 21681860. DOI: $10.1002 /$ stem.678

83 Hara K, Nakayama KI and Nakayama K: Geminin is essential for the development of preimplantation mouse embryos. Genes Cells 11: 1281-1293, 2006. PMID: 17054725. DOI: 10.1111/ j.1365-2443.2006.01019.x

84 Garzon R, Pichiorri F, Palumbo T, Visentini M, Aqeilan R, Cimmino A, Wang H, Sun H, Volinia S, Alder H, Calin GA, Liu $\mathrm{CG}$, Andreeff $\mathrm{M}$ and Croce CM: MicroRNA gene expression during retinoic acid-induced differentiation of human acute promyelocytic leukemia. Oncogene 26: 4148-4157, 2007. PMID: 17260024. DOI: 10.1038/sj.onc.1210186

85 Zhang J, Gao Y, Yu M, Wu H, Ai Z, Wu Y, Liu H, Du J, Guo Z and Zhang Y: Retinoic acid induces embryonic stem cell differentiation by altering both encoding RNA and microRNA expression. PLoS One 10: e0132566, 2015. PMID: 26162091. DOI: 10.1371 journal.pone.0132566
86 Beveridge NJ, Tooney PA, Carroll AP, Tran N and Cairns MJ: Down-regulation of miR-17 family expression in response to retinoic acid induced neuronal differentiation. Cell Signal 21: 18371845, 2009. PMID: 19666108. DOI: 10.1016/j.cellsig.2009.07.019

87 Meseguer S, Mudduluru G, Escamilla JM, Allgayer H and Barettino D: MicroRNAs-10a and $-10 \mathrm{~b}$ contribute to retinoic acid-induced differentiation of neuroblastoma cells and target the alternative splicing regulatory factor SFRS1 (SF2/ASF). J Biol Chem 286: 4150-4164, 2011. PMID: 21118818. DOI: 10.1074/ jbc.M110.167817

88 Zhang L, Cai M, Gong Z, Zhang B, Li Y, Guan L, Hou X, Li Q, Liu G, Xue Z, Yang MH, Ye J, Chin YE and You H: Geminin facilitates FoxO3 deacetylation to promote breast cancer cell metastasis. J Clin Invest 127: 2159-2175, 2017. PMID: 28436938. DOI: $10.1172 /$ JCI90077

89 Vlachakis D, Champeris Tsaniras S, Tsiliki G, Megalooikonomou $\mathrm{V}$ and Kossida S: Molecular modelling study of the 3D structure of the biglycan core protein, using homology modelling techniques. J Mol Biochem 2: 85-93, 2013.

90 Vlachakis D, Champeris Tsaniras S, Tsiliki G, Megalooikonomou $\mathrm{V}$ and Kossida S: 3D structural analysis of proteins using electrostatic surfaces based on image segmentation. J Mol Biochem 3: 27-33, 2014. PMID: 27525250.

91 Vlachakis D, Champeris Tsaniras S, Ioannidou K, Papageorgiou L, Baumann M and Kossida S: A series of Notch3 mutations in CADASIL; insights from 3D molecular modelling and evolutionary analyses. J Mol Biochem 3: 97-105, 2014.

92 Kostaropoulos T, Papageorgiou L, Champeris Tsaniras S, Vlachakis D and Eliopoulos E: Carcinogenic pesticide control via hijacking endosymbiosis; The paradigm of DSB-A from Wolbachia pipientis for the management of Otiorhynchus singularis. In Vivo 32: 1051-1062, 2018. PMID: 30150426. DOI: 10.21873/invivo.11346

93 Kuhn DE, Martin MM, Feldman DS, Terry AV, Nuovo GJ and Elton TS: Experimental validation of miRNA targets. Methods 44: 47-54, 2008. PMID: 18158132. DOI: 10.1016/j.ymeth.2007.09.005

Received April 25, 2019 Revised September 23, 2019 Accepted October 10, 2019 